\title{
Impact of litter quantity on the soil bacteria community during the decomposition of Quercus wutaishanica litter
}

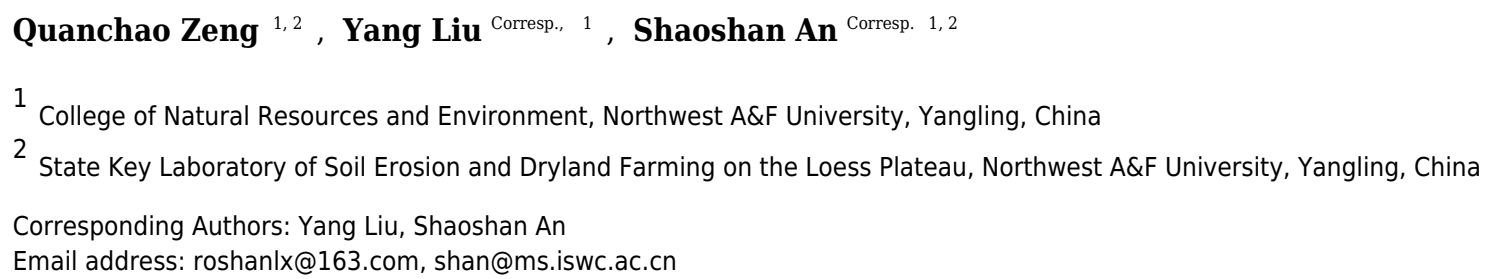

The forest ecosystem is the main component of terrestrial ecosystems. The global climate and the functions and processes of soil microbes in the ecosystem are all influenced by litter decomposition. The effects of litter decomposition on the abundance of soil microorganisms remain unknown. Here, we analyzed soil bacterial communities during the litter decomposition process in an incubation experiment under treatment with different litter quantities based on annual litterfall data (normal quantity, $200 \mathrm{~g} /(\mathrm{m} 2 / \mathrm{yr}$ ); double quantity, $400 \mathrm{~g} /(\mathrm{m} 2 / \mathrm{yr})$ and control, no litter). The results showed that litter quantity had significant effects on soil carbon fractions, nitrogen fractions, and bacterial community compositions, but significant differences were not found in the soil bacterial diversity. The normal litter quantity enhanced the relative abundance of Actinobacteria and Firmicutes and reduced the relative abundance of Bacteroidetes, Plantctomycets and Nitrospiare. The Beta-, Gamma-, and Deltaproteobacteria were significantly less abundant in the normal quantity litter addition treatment, and were subsequently more abundant in the double quantity litter addition treatment. The bacterial communities transitioned from Proteobacteria-dominant (Beta-, Gamma-, and Delta) to Actinobacteria-dominant during the decomposition of the normal quantity of litter. A cluster analysis showed that the double litter treatment and the control had similar bacterial community compositions. These results suggested that the double quantity litter limited the shift of the soil bacterial community. Our results indicate that litter decomposition alters bacterial dynamics under the accumulation of litter during the vegetation restoration process, which provides important significant guidelines for the management of forest ecosystems. 
1 Impact of litter quantity on the soil bacteria community during the decomposition of

2

\section{Quercus wutaishanica litter}

3 Quanchao Zeng 1,2, Yang Liu 1*, Shaoshan An 1,2*

4

5

$6{ }^{1}$ College of Natural Resources and Environment, Northwest A\&F University, Yangling, China

$7 \quad{ }^{2}$ State Key Laboratory of Soil Erosion and Dryland Farming on the Loess Plateau, Northwest

8 A\&F University, Yang ling, China

9

10

$11 *$ Corresponding author.

12

13

14

15

16

17

18

19

20

21

PeerJ reviewing PDF | (2017:04:17769:2:1:ACCEPTED 15 Aug 2017) 


\section{Abstract}

23 The forest ecosystem is the main component of terrestrial ecosystems. The global climate and the

24 functions and processes of soil microbes in the ecosystem are all influenced by litter

25 decomposition. The effects of litter decomposition on the abundance of soil microorganisms

26 remain unknown. Here, we analyzed soil bacterial communities during the litter decomposition

27 process in an incubation experiment under treatment with different litter quantities based on annual

28 litterfall data (normal quantity, $200 \mathrm{~g} /\left(\mathrm{m}^{2} / \mathrm{yr}\right)$; double quantity, $400 \mathrm{~g} /\left(\mathrm{m}^{2} / \mathrm{yr}\right)$ and control, no litter).

29 The results showed that litter quantity had significant effects on soil carbon fractions, nitrogen

30 fractions, and bacterial community compositions, but significant differences were not found in the

31 soil bacterial diversity. The normal litter quantity enhanced the relative abundance of

32 Actinobacteria and Firmicutes and reduced the relative abundance of Bacteroidetes,

33 Plantctomycets and Nitrospiare. The Beta-, Gamma-, and Deltaproteobacteria were significantly

34 less abundant in the normal quantity litter addition treatment, and were subsequently more

35 abundant in the double quantity litter addition treatment. The bacterial communities transitioned

36 from Proteobacteria-dominant (Beta-, Gamma-, and Delta) to Actinobacteria-dominant during the

37 decomposition of the normal quantity of litter. A cluster analysis showed that the double litter treatment and the control had similar bacterial community compositions. These results suggested that the double quantity litter limited the shift of the soil bacterial community. Our results indicate that litter decomposition alters bacterial dynamics under the accumulation of litter during the

41 vegetation restoration process, which provides important significant guidelines for the management of forest ecosystems. 


\section{Introduction}

Plant litter is the main source of soil carbon and nitrogen, and influences the function and development of terrestrial ecosystems (Sauvadet et al. 2016). The interaction between the soil and plant litter microorganism has attracted much attention (Urbanová et al. 2015). Microorganisms provide the link between the soil and plant and plays an important role in the soil biogeochemical recycle, including the recycling of carbon $(\mathrm{C})$, nitrogen $(\mathrm{N})$, phosphorus $(\mathrm{P})$ and other mineral elements (Keiluweit et al. 2015). Plants are the major sources of soil nutrients and affect soil properties via litter decomposition, root exudates and microorganism invasion from litter (Wardle et al. 2004). Litter decomposition is a key process for element recycling and had been studied by many researchers in different areas (Aerts 1997; Fanin et al. 2014; Freschet et al. 2013; Gundel et al. 2016; Kuramae et al. 2013; Sauvadet et al. 2016; van Huysen et al. 2016). Previous studies have shown litter quality and quantity are the main factors that drive the litter decomposition process (Keiluweit et al. 2015). Litter quality includes the C, N, P, Mn, Fe, Ca, Al, cellulose, hemi-cellulose and lignin content in the litter (Aerts 1997; Berg \& Mcclaugherty 2014; Keiluweit et al. 2015). Litter represents a major pathway for $\mathrm{C}$ cycling between the vegetation and the soil in terrestrial ecosystems, and changes in the aboveground litter quantity and quality could have important consequences for $\mathrm{C}$ cycling. Some researchers have reported that litter quantity increased litter decomposition, litter carbon (C) loss and soil respiration, but did not alter soil organic carbon content after 2.5 years in the forest system (Fang et al. 2015). Generally, the total $\mathrm{C}$ and $\mathrm{N}$ contents of soil is not sensitive to the litter decomposition process, but soil organisms have proved to be a sensitive indicator of the response of vegetation restoration (An et al. 2013; Huang et al. 2011). 
64 The quality of litter inputs determines on both the genetic structure of the soil microbial

65

66

67

68 communities and their substrate use patterns, which may have effects on soil microbial structure (Lamarche et al. 2007; Zhang et al. 2013). Thus, much more attention should be paid to the response of sensitive soil indicators to litter decomposition with the increase of the litter layer.

With the on-going Grain for Green project in China that began in 1999, plant coverage, plant biomass and the litter layer have gradually increased on the Loess Plateau (Deng et al. 2014). Enhanced soil quality and soil carbon storage have been reported by many researchers (An et al. 2013; Cheng et al. 2015; Deng et al. 2013). With the process of vegetation restoration, plant litters gradually accumulate, which may influence the function of soil microorganisms. Litter quantity is a key factor that can influence the function and composition of soil organisms. Higher plant litter quantities usually favor the growth of opportunistic bacterial taxa for the greater labile $\mathrm{C}$ compounds from litter (Nemergut et al. 2010). Thus, the accumulation of plant litter should theoretically enhance the biomass of soil microbes, in particular, organisms better that are suited to address the greater availability of $\mathrm{C}$ compounds via exploitative resource strategies (Nemergut et al. 2010). However, the relative effects of litter quantity on the soil bacterial structure have rarely been assessed, and to our knowledge, there are no studies disentangling the effects of litter quantity on the soil bacteria during the decomposition processes in forest soils.

81 With the objective of disentangling the effects of litter quantity on soil bacterial structure and function, we analyzed the soil community structure and diversity in an incubation experiment with different litter quantities, including normal and double levels based on the data from annual litter fall. Illumina Hiseq sequencing was used to determine the response of the soil bacterial community 
85

86

87

to different amounts of litter decomposition. We hypothesized that (1) litter decomposition may enhance the soil bacterial diversity and community composition, especially for the oligotrophic bacteria and (2) this trend increase with the increase of litter quantity as more nutrients are available from litter decomposition. Our results provide insights to better understand the process of litter decomposition and to manage forest land with accumulated plant litter.

\section{Materials and Methods}

\subsection{Site description}

Soil and litter samples were collected from the Fuxian Observatory for Soil Erosion and Ecoenvironment, a secondary forest region. Quercus wutaishanica was the predominant community, playing an important role in maintaining the stability of the system in this area (Fan et al. 2006; Guo et al. 2010). Therefore, understanding the effects of Quercus wutaishanica leaf litter decomposition provides insights into the carbon and nitrogen recycling in the soil-plant system. We established three plots in Quercus wutaishanica forests with similar topographical conditions to investigate the annual litter fall using the method described by Ukonmaanaho \& Starr (2001) (Ukonmaanaho \& Starr 2001). Over two years of observations, the annual litter fall of Quercus wutaishanica was approximately $200 \mathrm{~g} / \mathrm{m}^{2} / \mathrm{yr}$.

\subsection{Soil and litter sampling}

Soil samples from 0-20 cm were obtained in September 2015 when most of the leaves had fallen. All roots, stones, small animals and other debris were removed from the soil samples by hand, and the samples were sieved through a $2-\mathrm{mm}$ screen. The mixed soils were used to conduct the litter decomposition experiment in the laboratory. The soil organic carbon and total nitrogen 
106

107

108

109

110

111

112

113

114

115

116

117

118

119

120

121

122

123

124

125

126

contents were $18.26 \mathrm{~g} / \mathrm{kg}$ and $1.60 \mathrm{~g} / \mathrm{kg}$, respectively. Fresh litter was collected with a litter collector. To avoid damaging the litter structure, the leaves were air-dried for more than two weeks at room temperature to a consistent weight.

\subsection{Litter decomposition experiment}

Litter decomposition experiment was conducted using the nylon mesh bag technique. There were three treatments, including normal quantity $\left(200 \mathrm{~g} /\left(\mathrm{m}^{2} / \mathrm{yr}\right)\right)$ litter, double quantity (400 $\mathrm{g} /\left(\mathrm{m}^{2} / \mathrm{yr}\right)$ ) litter, and control (no litter) (Fig. 1). The litter bags $(10 \mathrm{~cm} \times 20 \mathrm{~cm}$ size) were constructed out of $1 \mathrm{~mm}$ nylon mesh. First, we placed $200 \mathrm{~g}$ fresh soils in a $1 \mathrm{~L}$ plastic basin and then placed a litter bag ( $5 \mathrm{~g}$, normal quantity; $10 \mathrm{~g}$, double quantity) on the surface. Each treatment had three replicates. We also conducted a control experiment without litter bags. All basins were incubated at $25{ }^{\circ} \mathrm{C}$ in an incubator. The soil water content was adjusted using the weighting method every week at a relative humidity of $20 \%$. After 90 days, we collected the soil sample layer below the litter bags to analyze the soil properties and bacterial communities. After harvest, each soil sample was mixed and separated into two parts. One part was air-dried for the evaluation of the soil properties. The other part was frozen at $-80{ }^{\circ} \mathrm{C}$ (using liquid nitrogen) for subsequent sequencing analysis.

\subsection{Analysis of the soil properties}

The soil moisture was determined gravimetrically with fresh soils at $105{ }^{\circ} \mathrm{C}$ for $24 \mathrm{~h}$, and the water content was expressed as a percentage of the dry weight. The fumigation-extraction method was used to determine microbial biomass carbon (MBC) and microbial nitrogen (MBN) (Vance et al. 1987). The dissolved carbon (DOC) and dissolved nitrogen (DON) in the soil were determined 
127 by extracting the samples in $0.5 \mathrm{~mol} / \mathrm{L} \mathrm{K}_{2} \mathrm{SO}_{4}$. The soil total $\mathrm{N}(\mathrm{STN})$, soil organic carbon (SOC), 128 soil nitrate nitrogen $\left(\mathrm{NO}_{3}{ }^{-}-\mathrm{N}\right)$ and soil ammonia nitrogen $\left(\mathrm{NH}_{4}{ }^{+}-\mathrm{N}\right)$ were analyzed using the 129 method described by Zeng et al. (2016) (Zeng et al. 2016).

130

131

132

\subsection{Soil NDA extraction and PCR amplification}

The DNA of the soil was extracted from a $0.5 \mathrm{~g}$ soil sample using the CTAB method. The concentration and purity of the DNA were monitored using 1\% agarose gels. According to the concentration, the DNA samples were diluted to $1 \mathrm{ng} / \mu \mathrm{L}$ with sterile water to reduce the effects of the PCR inhibitors. The V4 gene of the $16 \mathrm{~S}$ rRNA was amplified using the 515F /806R primer sets (Bergmann et al. 2011; Zeng et al. 2017). All PCR reactions were carried out with Phusion® High-Fidelity PCR Master Mix (New England Biolabs). The same volume of $1 \times$ loading buffer (contained SYB green) was mixed with the PCR products, and electrophoresis was conducted on $2 \%$ agarose gels for detection. The samples with a bright strip between $400-450$ bp were chosen for further experiments. The PCR products were mixed at equal density ratios. Then, the PCR mixtures were purified using a Qiagen Gel Extraction Kit (Qiagen, Germany).

\subsection{Illumina Miseq sequencing}

Sequencing libraries were generated using a TruSeq® DNA PCR-Free Sample Preparation Kit (Illumina, USA) following the manufacturer's recommendations and index codes were added. The library quality was assessed on the Qubit@ 2.0 Fluorometer (Thermo Scientific) and Agilent Bioanalyzer 2100 system. Finally, the library was sequenced on an Illumina HiSeq 2500 platform and 250 bp paired-end reads were generated. The $16 \mathrm{~S}$ rRNA gene amplicon sequencing was conducted at Novogene Bioinformatics Technology Co., Ltd., Beijing, China. The raw sequence 
148

149

150

151

152

153

154

155

156

157

158

159

160

161

162

163

164

165

166

167

168

data in FASTQ format are accessible from the NCBI SRA with the number of SRP107086.

\subsection{Statistical and bioinformatics analysis}

QIIME software was used to analyze the sequences data (Caporaso et al. 2010). The sequencing data yielded 569171 raw reads, with 71146 raw reads per sample. After removing the low quality reads and trimming the barcodes and primers, there were 545740 valid reads (average length $253 \mathrm{bp}$ ). Clustering sequences at 97\% similarity levels were assigned to the same OTUs

(Stackebrandt \& Goebel 1994). After the removal of chimeric sequences, a total of 4833 different OTUs were recorded. Taxonomy was assigned to each OTU via the Ribosomal Database Project (RDP) classifier (Cole et al. 2009). The representative sequence for each OTU was screened for further annotation. The abundance of OTUs information was normalized using a standard sequence number corresponding to the sample with the fewest sequences. The alpha diversity was applied to analyze the complexity of the species diversity of each sample, including the observed-species index and the Shannon index. All indices in our samples were calculated with QIIME (Version1.7.0) and displayed with R software (Version 2.15.3).

The similarities between treatments were measured using a principal coordinate analysis (PCoA) plot. The PCoA was analyzed using the WGCNA, stat and ggplot2 packages in R software (Version 2.15.3). One-way ANOSIM and SIMPER analysis were used to compare the differences in the bacterial composition among the different treatments using the Bray-Curtis method (PRIMER software v 7) (Zeng et al. 2017). A higher R value in ANOSIM indicated a higher separation between the treatments. The linear discriminant analysis effect size (LEfSe) method was used to determine the difference between the normal and the double litter amount treatments 
169 (Segata et al. 2011). One-way ANOVA was performed to explore the differences between the soil 170 properties and the soil bacterial compositions under the different treatments (SPSS version 20.0 171 for Windows), and the Student-Newman-Keuls (SKN) method was used for the comparison $172(\mathrm{P}=0.05)$. The relationships between soil bacterial composition and the environmental factors were tested using Pearson correlation analyses using SPSS 20.0 for Windows.

\section{Results}

3.1 Soil chemical properties and the response of microbial biomass to litter decomposition and an increase in double treatment. No significant differences were observed among the treatments for soil $\mathrm{NH}_{4}{ }^{+}-\mathrm{N}$, which ranged from 5.39 to $5.73 \mathrm{mg} / \mathrm{kg}$. The $\mathrm{MBN}$ content was significantly higher in the normal treatment and ranged from 43.50 to $124.14 \mathrm{mg} / \mathrm{kg}$, and was in the order of normal $>$ double $>$ control. The DON showed the opposite trend to the MBN, with the highest value measured in the control treatment. The soil nitrate nitrogen ranged from 21.98 to $27.90 \mathrm{mg} / \mathrm{kg}$, and there was no significant difference between the normal and the control treatments. The control treatment had the highest $\mathrm{MBC}$ and the lowest DOC, and was significantly different from the double treatment. With the increase of litter quantity, the soil nitrate nitrogen, soil moisture, MBC, DOC and DON showed significant reductions in the normal treatment, and a significant increase was observed in the MBN.

\subsection{Response of the soil bacterial community activity to litter decomposition}


The bacterial diversity indices showed no significant changes between the different

treatments (Table 1), but the soil bacterial community compositions demonstrated significant

structuring in response to litter addition. The most dominant groups across all soil samples were

Proteobacteria (38-42\%), Actinobacteria (11-21\%), Acidobacteria (18-20\%), Gemmatimonadetes

194 (5\%), Bacteroidetes (4-6\%), Chloroflexi (3\%), Firmicutes (1-2\%), Verrucomicrobia (2-4\%),

195 Planctomycetes (3-4\%) and Nitrospirae (2\%) (Fig. 3). The relative abundance of Actinobacteria,

Bacteroidetes, Planctomycetes, Firmicutes and Nitrospirae in the normal treatment was

197

198

199

200

201

202

203

204

205

206

207

208

209

210

significantly higher than in the double and control treatments (Fig. 3-A).

To explore the dynamics of the major microbial taxa under different mounts of litter treatment, we found that Alpha, Beta, Gamma, and Delta-proteobacteria were the main members of Proteobacteria. Only Alpha-proteobacteria showed no significant differences among the different treatments, and ranged from 15.50 to $17.82 \%$. With the increase of litter quantity, the relative abundance of Bet, Gamma, and Deltaproteobacteria showed a decrease in the normal treatment, and an increase in the double treatment. The Beta, Gamma, and Deltaproteobacteria occupied $5.75 \%, 6.00 \%$, and $6.93 \%$, respectively, in the normal treatment, which significantly differed from the double and control treatment (Fig 3-B). At the order level, Subgroup_6 and Subgroup_4 were the dominant taxa in the Acidobacteria phylum, and showed no significant changes with the increase of litter quantity. Rhizobiales was the dominant taxa of Alphaproteobacteria, and ranged from 7.01 to $8.75 \%$, and showed similar variation to those of the Alphaproteobacteria. Solirubrobacterales, Xanthomonadales, Sphingobacteriales, Myxococcales and Gaiellales had significant differences among the litter addition treatments (Fig. 4). These 
211 differences were only detected between the normal treatment and the double or the control

212 treatment. The cluster analysis and PCoA also indicted these changes (Fig. 3 and Fig. 5). More

213 specifically, the bacterial community profiles in normal treatment trended to group together and

214 were separated from those in the double and control treatments. A t-test showed that the soil

215 bacterial taxa were significantly different between the normal and the double treatments, including

216 Proteobacteria (Xanthomonadales, Salinisphaerales, Legionellales, Chromatiales,

217 Syntrophobacterales, Sh765B-TzT-29, Myxococcales, SC-I-84, Sneathiellales, DB1-14 and

218 Caulobacterales), Planctomycetes (WD2101_soil_group, Phycisphaerales, CCM11a), and

219 Actinobacteria (Micrococcales, Solirubrobacterales, Rubrobacterales and Acidimicrobiales) (Fig.

$2205)$.

221

The ANOSIM based on the OTUs of the 16S rRNA gene sequences indicated that the differences were significant between the different litter addition treatments (ANOSIM Global $\mathrm{R}=$

0.761, $\mathrm{P}=0.01)$. SIMPER analysis revealed that bacterial communities were $76-81 \%$ similar

between the normal, double and control treatments. The LEfSe analyses identified the significant

difference in the abundant taxa between the different litter quantity treatments. Using the LEfSe,

we found that Bacteroidetes, Myxococcales and Deltaproteobacteria were primarily different in

the high-litter treatment (double). The green color in Fig.6 indicates the significantly different taxa

in the normal treatment, and these species could potentially be used as biomarkers in the normal

229 quantity treatment (Fig. 6).

230 Pearson correlation analysis showed that soil moisture, DON and MBN were the factors that 
232 significantly correlated with the relative abundance of Actinobacteria, Bacteroidetes,

233 Verrucomicrobia, Verrucomicrobia, Firmicutes and Nitrospirae, with coefficients of -0.684, 0.812,

$2340.679,0.669,-0.804$ and 0.715 , respectively. The SM and MBN were similarly correlated with the

235 bacterial community composition (Table 2). There were no significant correlations with the

236 relative abundance of Acidobacteria, Gemmatimonadetes and Chloroflexi, as the abundance of

237 these taxa was stable among the different treatments.

\section{Discussion}

Plant litter decomposition is a key process of in the recycling of soil elements (Berg \&

Mcclaugherty 2014). In this study, the SOC and STN contents were not significantly altered by

litter decomposition (Fig. 2). This result is not consistent with other litter decomposition studies.

This study was a short-term experiment (only three months), generally, while total $\mathrm{C}$ and $\mathrm{N}$ accumulation in soil occurs over long term processes with different mechanisms. However, the available nutrients in soil, such as nitrite nitrogen and dissolved nitrogen, were significantly altered by litter decomposition. Litter decomposition altered the available soil $\mathrm{N}$ fractions (. i.e., MBN, DON and $\mathrm{NO}_{3}-\mathrm{N}$ ), and provided $\mathrm{N}$ resources for the growth of microbial organisms (Cleveland \&

247 Townsend 2006; Wardle et al. 2004). The MBC and DOC also differed between the different treatments. These changes revealed that the available $\mathrm{C}$ and $\mathrm{N}$ concentrations in the soil were sensitive to litter decomposition, which could help to estimate and evaluate the effects of litter decomposition under global climate change, $\mathrm{N}$ deposition, extreme drought and other environmental problems. 
253 normal quantity treatment than in the double treatment, but the bacterial diversity did not differ

254 significantly (Shannon and observed-species indices). Short-term litter decomposition increased

255 the relative abundance of Actinobacteria, Firmicutes and Thermoleophilia, and decreased the

256 relative abundance of Deltaproteobacteria, Gammaproteobacteria, Betaproteobacteria and

257 Sphingobacteriia, which is most likely a result of the available $\mathrm{C}$ and $\mathrm{N}$ input via litter deposition

258 caused by soil or litter microorganisms (Cleveland \& Townsend 2006; Wardle et al. 2004). Soil

259 copiotrophic Bacteroidetes, $\alpha$-, $\beta$-, and $\gamma$-Proteobacteria were relatively more abundant in the

260 control and the double quantity litter treatment soils. The available nutrients released by the litter

261 stimulated the microbial production of extracellular enzymes (Koyama et al. 2013), resulting in

262 increased $\mathrm{C}$ and $\mathrm{N}$ availability, which also altered the bacterial community composition. Zhang et

al. (2016) (Zhang et al. 2016) also observed that soil Proteobacteria increased with succession in

Loess Plateau grasslands, as the soil nutrients were enhanced across the succession. In addition,

our results indicated that soil water content significantly increased with the quantity of litter (Table

1). Increased water availability should alter soil microbial processes such as litter decomposition

and nutrient mineralization (DeAngelis et al. 2015). These results suggest that nutrient and water

availability in the soil may help explain why the increase in litter input altered the soil bacterial community composition in the normal and control treatments.

Bacteria play an important role in the litter decomposition process. Most Alphaproteobacteria,

Acidobacteria and Actinobacteria can degrade recalcitrant $\mathrm{C}$ in plant litter (Barret et al. 2011).

Acidobacteria can grow on complex polymers, including plant hemicellulose or cellulose and 
274 changed. These changes were indicated between the control and the normal treatments. The cluster

275 tree analysis, PCoA and one-way ANOSIM all indicated that double and control treatments had

276 similar bacterial communities (Figs. 3 and 5, Table 3). These results were consistent with the

277 results of the LEefSe analysis and taxa abundance. Based on the results of LEefSe analysis

278 indicated that Gaiellaes, Solirubrobacterales, Thermoleophilia and Alphaproteobacteria were

279 significantly different in the normal treatment, and Shphingobacteria, Myxococcales and

280 Deltaproteobacteria were significantly different in double treatment, which suggested that litter

281 addition had significant effects on certain bacterial species (Fanin et al. 2014; Mau et al. 2015).

282 The abundance of soil microbes was based on the nutritional preferences and functions of the microbes (Banerjee et al. 2016; Mau et al. 2015). The normal amount of litter addition altered the priming effects of soil bacterial communities, which has been confirmed by other researchers

(Banerjee et al. 2016). Litter addition enhanced the decomposition of soil organic matter and altered the abundance of functional groups, as seen by the decline of copiotrophic bacteria. The double litter addition treatment did not alter the soil bacterial composition, as much more liable nutrients from litter decomposition could maintain the growth of copiotrophic bacteria.

Soil available nutrients may be the primary difference caused by these shifts. Zhong et al. (2015) (Zhong et al. 2015) found that $\mathrm{N}$ addition caused changes of the soil bacterial and fungal communities in a long term field experiment. The SOC was another main factor that affected the affecting soil bacterial community composition. Liu et al. (2014) found that Actinobacteria was significantly positively related to SOC, and Deltaproteobacteria was significantly negatively related to SOC (Liu et al. 2014). However, similar results were not observed in this study, which 
295

296

297

298

299

300

301

302

303

304

305

306

307

308

309

310

311

312

313

314

315

was in accordance with the results from Zhong et al. (2015) (Zhong et al. 2015). We also found that soil total $\mathrm{N}$ had no significant effect on soil community structure, but soil available $\mathrm{N}$ was significantly related to the soil bacterial community. Soil available $\mathrm{N}$ is the main resource for soil bacterial growth, which caused the variation in soil bacterial community structure. Zhang et al. (2016) (Zhang et al. 2016) reported that the soil nitrate nitrogen content was significantly related to the soil bacterial community along a natural succession. Yao et al. (2014) (Yao et al. 2014) found that the soil ammonium nitrogen content played an important role in the soil bacterial community compositions in the grass land soils of China. Yuan et al. (2014) (Yuan et al. 2014) also observed similar results in soil on the Tibetan Plateau. All these results confirmed that soil available $\mathrm{N}$ content was the main factor that drove these changes in the soil bacterial communities.

\section{Conclusion}

These results suggested that normal litter quantity could alter soil bacterial community compositions. A higher quantity of litter did not affect the soil microbial community. Beta, Gamma, and Deltaproteobacteria were significantly decreased in the normal quantity litter addition treatment, and subsequently increased in the double quantity litter addition treatment. The bacterial communities transitioned from Proteobacteria-dominant (Beta-, Gamma-, and Delta) to Actinobacteria-dominant during decomposition of the normal quantity of litter. The soil available nutrients and the soil copiotrophic bacterial communities were higher in the control and the double quantity of litter decomposition treatments. These results suggested that litter addition affected the soil bacterial structure, and can provide guidance to manage vegetation restoration with the increase of litter quantity. 
316

317

318

319

320

321

322

323

324

325

326

327

328

329

330

331

332

333

334

335

336

337

338

339

340

341

342

343

344

345

346

347

348

349

350

351

352

353

354

355

\section{References}

Aerts R. 1997. Climate, leaf litter chemistry and leaf litter decomposition in terrestrial ecosystems: a triangular relationship. Oikos:439-449.

An SS, Cheng Y, Huang YM, and Liu D. 2013. Effects of Revegetation on Soil Microbial Biomass, Enzyme Activities, and Nutrient Cycling on the Loess Plateau in China. Restoration Ecology 21:600-607.

Banerjee S, Baah - Acheamfour M, Carlyle CN, Bissett A, Richardson AE, Siddique T, Bork EW, and Chang SX. 2016. Determinants of bacterial communities in Canadian agroforestry systems. Environmental microbiology 18:1805-1816.

Barret M, Morrissey JP, and O'Gara F. 2011. Functional genomics analysis of plant growth-promoting rhizobacterial traits involved in rhizosphere competence. Biology and Fertility of Soils 47:729-743.

Berg B, and Mcclaugherty C. 2014. Plant Litter. Decomposition, Humus Formation, Carbon Sequestration.

Bergmann GT, Bates ST, Eilers KG, Lauber CL, Caporaso JG, Walters WA, Knight R, and Fierer N. 2011. The underrecognized dominance of Verrucomicrobia in soil bacterial communities. Soil biology and biochemistry 43:1450-1455.

Caporaso JG, Kuczynski J, Stombaugh J, Bittinger K, Bushman FD, Costello EK, Fierer N, Peña AG, Goodrich JK, and Gordon JI. 2010. QIIME allows analysis of high-throughput community sequencing data. Nature methods 7:335-336.

Cheng M, Xiang Y, Xue Z, An S, and Darboux F. 2015. Soil aggregation and intra-aggregate carbon fractions in relation to vegetation succession on the Loess Plateau, China. Catena 124:77-84.

Cleveland CC, and Townsend AR. 2006. Nutrient additions to a tropical rain forest drive substantial soil carbon dioxide losses to the atmosphere. Proceedings of the National Academy of Sciences 103:10316-10321.

Cole JR, Wang Q, Cardenas E, Fish J, Chai B, Farris RJ, Kulam-Syed-Mohideen A, McGarrell DM, Marsh T, and Garrity GM. 2009. The Ribosomal Database Project: improved alignments and new tools for rRNA analysis. Nucleic acids research 37:D141-D145.

DeAngelis KM, Pold G, Topçuoğlu BD, van Diepen LT, Varney RM, Blanchard JL, Melillo J, and Frey SD. 2015. Long-term forest soil warming alters microbial communities in temperate forest soils. Frontiers in microbiology 6:104.

Deng L, Liu GB, and Shangguan ZP. 2014. Land-use conversion and changing soil carbon stocks in China's 'Grainfor-Green' Program: a synthesis. Global Change Biology 20:3544-3556.

Deng L, Shangguan Z-P, and Sweeney S. 2013. Changes in soil carbon and nitrogen following land abandonment of farmland on the Loess Plateau, China. Plos One 8:e71923.

Eichorst SA, Kuske CR, and Schmidt TM. 2011. Influence of plant polymers on the distribution and cultivation of bacteria in the phylum Acidobacteria. Applied and environmental microbiology 77:586-596.

Fan W-Y, Wang X-A, and Guo H. 2006. Analysis of plant community successional series in the Ziwuling area on the Loess Plateau. Acta Ecologica Sinica 26:706-714.

Fang X, Zhao L, Zhou G, Huang W, and Liu J. 2015. Increased litter input increases litter decomposition and soil respiration but has minor effects on soil organic carbon in subtropical forests. Plant and soil 392:139-153.

Fanin N, Hättenschwiler S, and Fromin N. 2014. Litter fingerprint on microbial biomass, activity, and community structure in the underlying soil. Plant and soil 379:79-91.

Freschet GT, Cornwell WK, Wardle DA, Elumeeva TG, Liu W, Jackson BG, Onipchenko VG, Soudzilovskaia NA, 
356

357

358

359

360

361

362

363

364

365

366

367

368

369

370

371

372

373

374

375

376

377

378

379

380

381

382

383

384

385

386

387

388

389

390

391

392

393

394

395

396

Tao J, and Cornelissen JH. 2013. Linking litter decomposition of above - and below - ground organs to plant - soil feedbacks worldwide. Journal of Ecology 101:943-952.

Gundel P, Helander M, Garibaldi L, Vazquez-de-Aldana B, Zabalgogeazcoa I, and Saikkonen K. 2016. Role of foliar fungal endophytes in litter decomposition among species and population origins. Fungal Ecology 21:50-56.

Guo H, Wang XA, Zhu ZH, Wang SX, and Guo JC. 2010. Seed and microsite limitation for seedling recruitment of Quercus wutaishanica on Mt. Ziwuling, Loess Plateau, China. New Forests 41:127-137.

Huang YM, Michel K, An SS, and Zechmeister-Boltenstern S. 2011. Changes in microbial-community structure with depth and time in a chronosequence of restored grassland soils on the Loess Plateau in northwest China. Journal of Plant Nutrition and Soil Science 174:765-774.

Keiluweit M, Nico P, Harmon ME, Mao J, Pett-Ridge J, and Kleber M. 2015. Long-term litter decomposition controlled by manganese redox cycling. Proceedings of the National Academy of Sciences 112:E5253-E5260.

Koyama A, Wallenstein MD, Simpson RT, and Moore JC. 2013. Carbon-degrading enzyme activities stimulated by increased nutrient availability in arctic tundra soils. PLoS One 8:e77212.

Kuramae EE, Hillekens RH, de Hollander M, van der Heijden MG, van den Berg M, van Straalen NM, and Kowalchuk GA. 2013. Structural and functional variation in soil fungal communities associated with litter bags containing maize leaf. FEMS microbiology ecology 84:519-531.

Lamarche J, Bradley RL, Hooper E, Shipley B, Beaunoir A-MS, and Beaulieu C. 2007. Forest floor bacterial community composition and catabolic profiles in relation to landscape features in Québec's southern boreal forest. Microbial ecology 54:10-20.

Liu J, Sui Y, Yu Z, Shi Y, Chu H, Jin J, Liu X, and Wang G. 2014. High throughput sequencing analysis of biogeographical distribution of bacterial communities in the black soils of northeast China. Soil biology and biochemistry 70:113-122.

Mau RL, Liu CM, Aziz M, Schwartz E, Dijkstra P, Marks JC, Price LB, Keim P, and Hungate BA. 2015. Linking soil bacterial biodiversity and soil carbon stability. The ISME Journal 9:1477.

Nemergut DR, Cleveland CC, Wieder WR, Washenberger CL, and Townsend AR. 2010. Plot-scale manipulations of organic matter inputs to soils correlate with shifts in microbial community composition in a lowland tropical rain forest. Soil biology and biochemistry 42:2153-2160.

Sauvadet M, Chauvat M, Fanin N, Coulibaly S, and Bertrand I. 2016. Comparing the effects of litter quantity and quality on soil biota structure and functioning: Application to a cultivated soil in Northern France. Applied Soil Ecology 107:261-271.

Segata N, Izard J, Waldron L, Gevers D, Miropolsky L, Garrett WS, and Huttenhower C. 2011. Metagenomic biomarker discovery and explanation. Genome biology 12:R60.

Stackebrandt E, and Goebel B. 1994. Taxonomic note: a place for DNA-DNA reassociation and 16S rRNA sequence analysis in the present species definition in bacteriology. International Journal of Systematic and Evolutionary Microbiology 44:846-849.

Ukonmaanaho L, and Starr M. 2001. The importance of leaching from litter collected in litterfall traps. Environmental monitoring and assessment 66:129-146.

Urbanová M, Šnajdr J, and Baldrian P. 2015. Composition of fungal and bacterial communities in forest litter and soil is largely determined by dominant trees. Soil biology and biochemistry 84:53-64.

van Huysen TL, Perakis SS, and Harmon ME. 2016. Decomposition drives convergence of forest litter nutrient stoichiometry following phosphorus addition. Plant and soil:1-14.

PeerJ reviewing PDF | (2017:04:17769:2:1:ACCEPTED 15 Aug 2017) 
397

398

399

400

401

402

403

404

405

406

407

408

409

410

411

412

413

414

415

416

417

418

419

420

421

422

423

424

425

426

427
Vance E, Brookes P, and Jenkinson D. 1987. An extraction method for measuring soil microbial biomass C. Soil biology and biochemistry 19:703-707.

Wardle DA, Bardgett RD, Klironomos JN, Setälä H, Van Der Putten WH, and Wall DH. 2004. Ecological linkages between aboveground and belowground biota. Science 304:1629-1633.

Yao M, Rui J, Li J, Dai Y, Bai Y, Heděnec P, Wang J, Zhang S, Pei K, and Liu C. 2014. Rate-specific responses of prokaryotic diversity and structure to nitrogen deposition in the Leymus chinensis steppe. Soil biology and biochemistry 79:81-90.

Yuan Y, Si G, Wang J, Luo T, and Zhang G. 2014. Bacterial community in alpine grasslands along an altitudinal gradient on the Tibetan Plateau. FEMS microbiology ecology 87:121-132.

Zeng Q, An S, and Liu Y. 2017. Soil bacterial community response to vegetation succession after fencing in the grassland of China. Science of The Total Environment 609:2-10.

Zeng Q, Xin L, Dong Y, An S, and Darboux F. 2016. Soil and plant components ecological stoichiometry in four steppe communities in the Loess Plateau of China. Catena 147:481-488.

Zhang B, Wang H, Yao S, and Bi L. 2013. Litter quantity confers soil functional resilience through mediating soil biophysical habitat and microbial community structure on an eroded bare land restored with mono Pinus massoniana. Soil biology and biochemistry 57:556-567.

Zhang C, Liu G, Xue S, and Wang G. 2016. Soil bacterial community dynamics reflect changes in plant community and soil properties during the secondary succession of abandoned farmland in the Loess Plateau. Soil biology and biochemistry 97:40-49.

Zhong Y, Yan W, and Shangguan Z. 2015. Impact of long-term N additions upon coupling between soil microbial community structure and activity, and nutrient-use efficiencies. Soil biology and biochemistry 91:151-159.

\section{8}


428

429

430

431
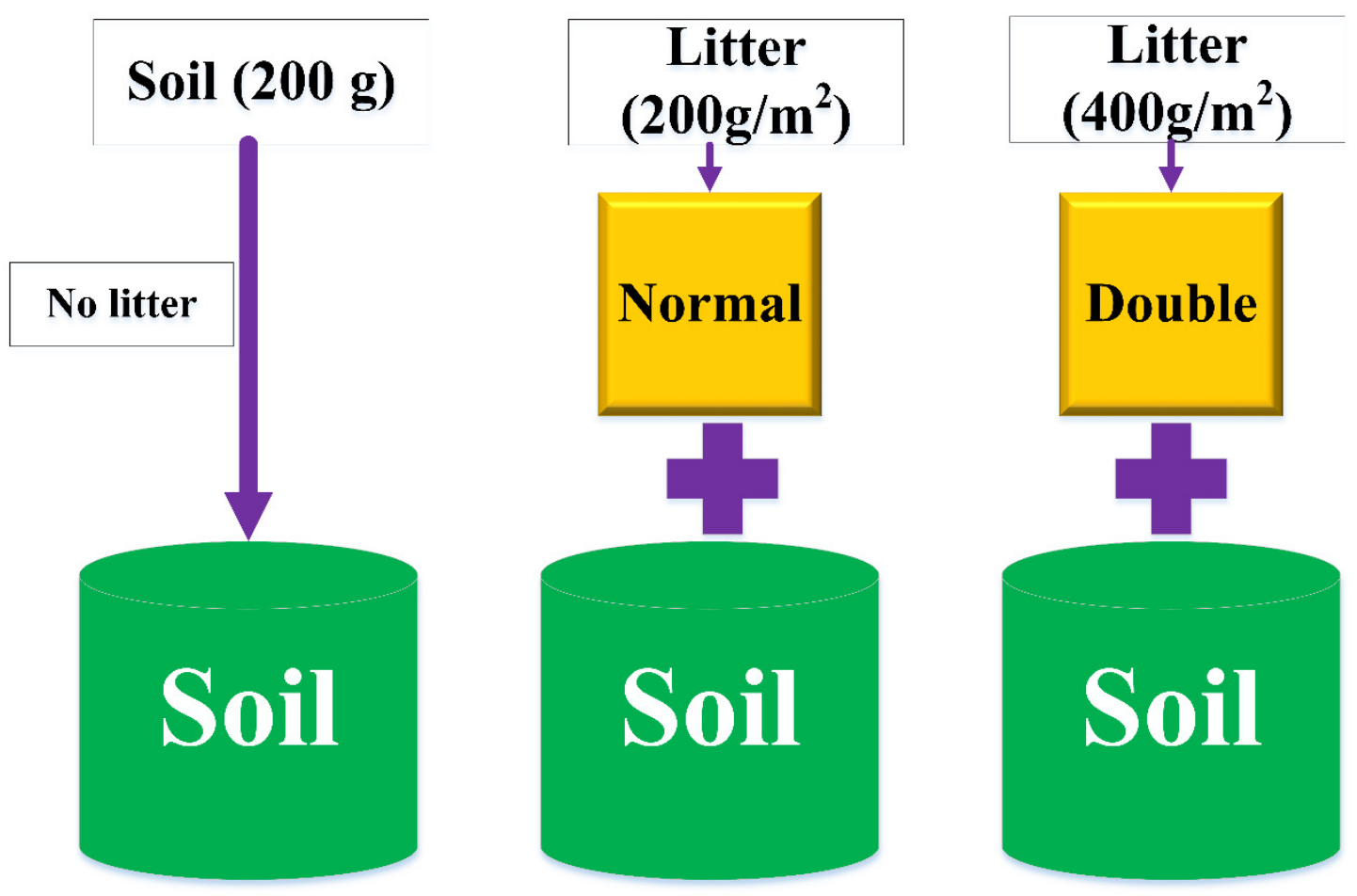

Fig. 1 The setup of the litter decomposition experiment under different litter quantities. 

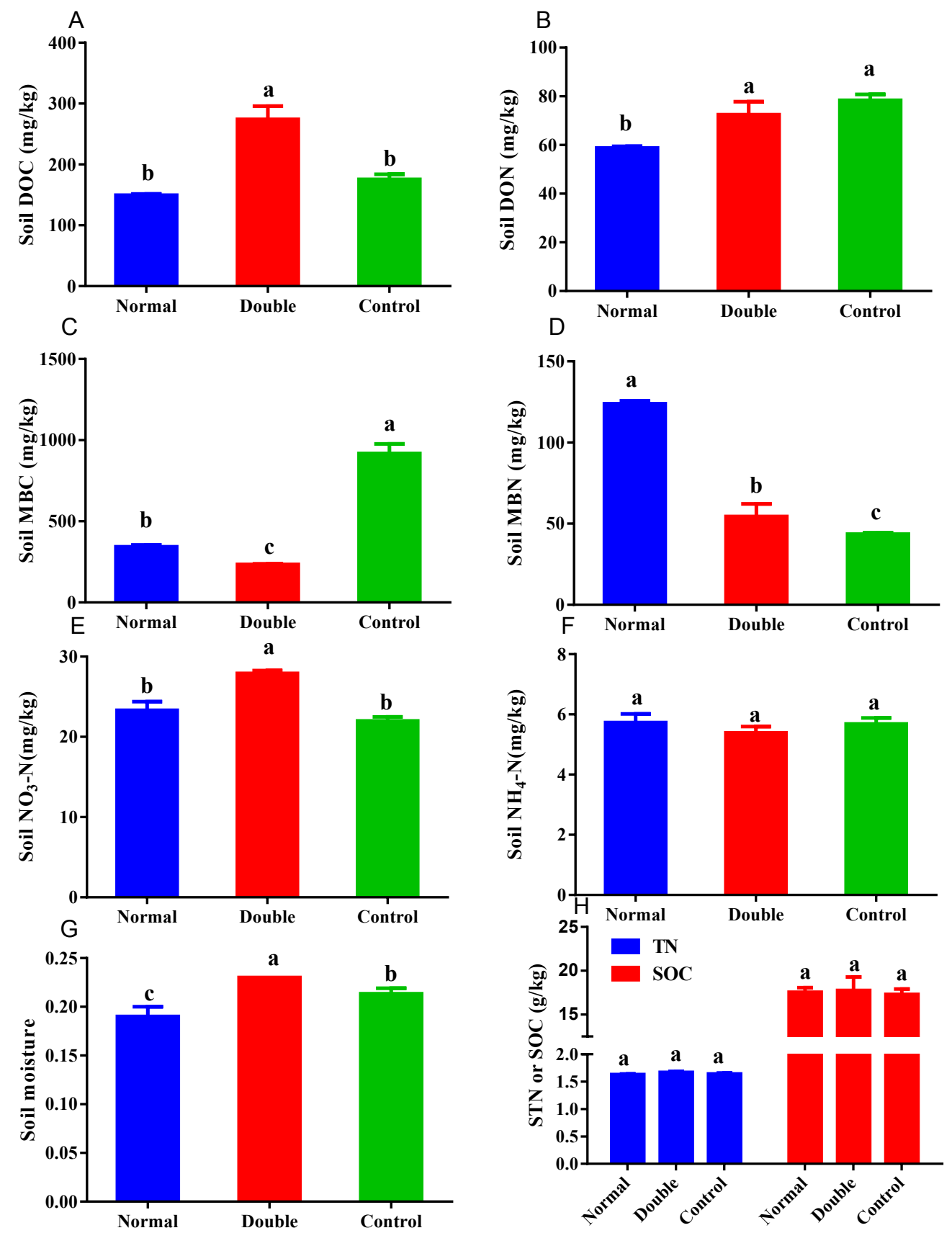

435 Fig. 2 Soil carbon and nitrogen fractions in the different treatments. Different lowercase letters indicate significant differences at the 0.05 level. All data are expressed as means \pm SD 
A
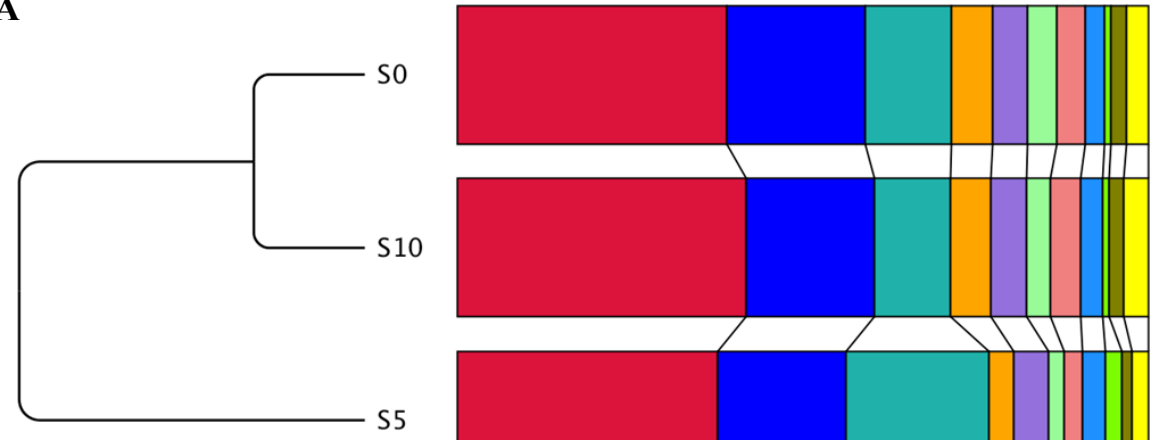

oteobacteria

Acidobacteria

$\square$ Actinobacteria

$\square$ Bacteroidetes

$\square$ Gemmatimonadetes

$\square$ Verrucomicrobia

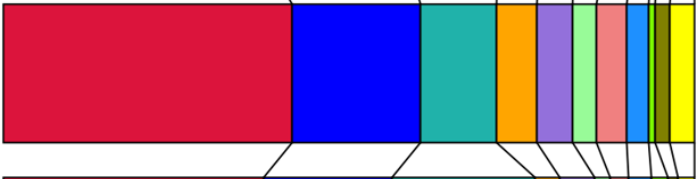

Planctomycetes

$\square$ Chloroflexi

$\square$ Firmicutes

$\square$ Nitrospirae

$\square$ Others

Weighted Unifrac Distance سلسسلس 0.06
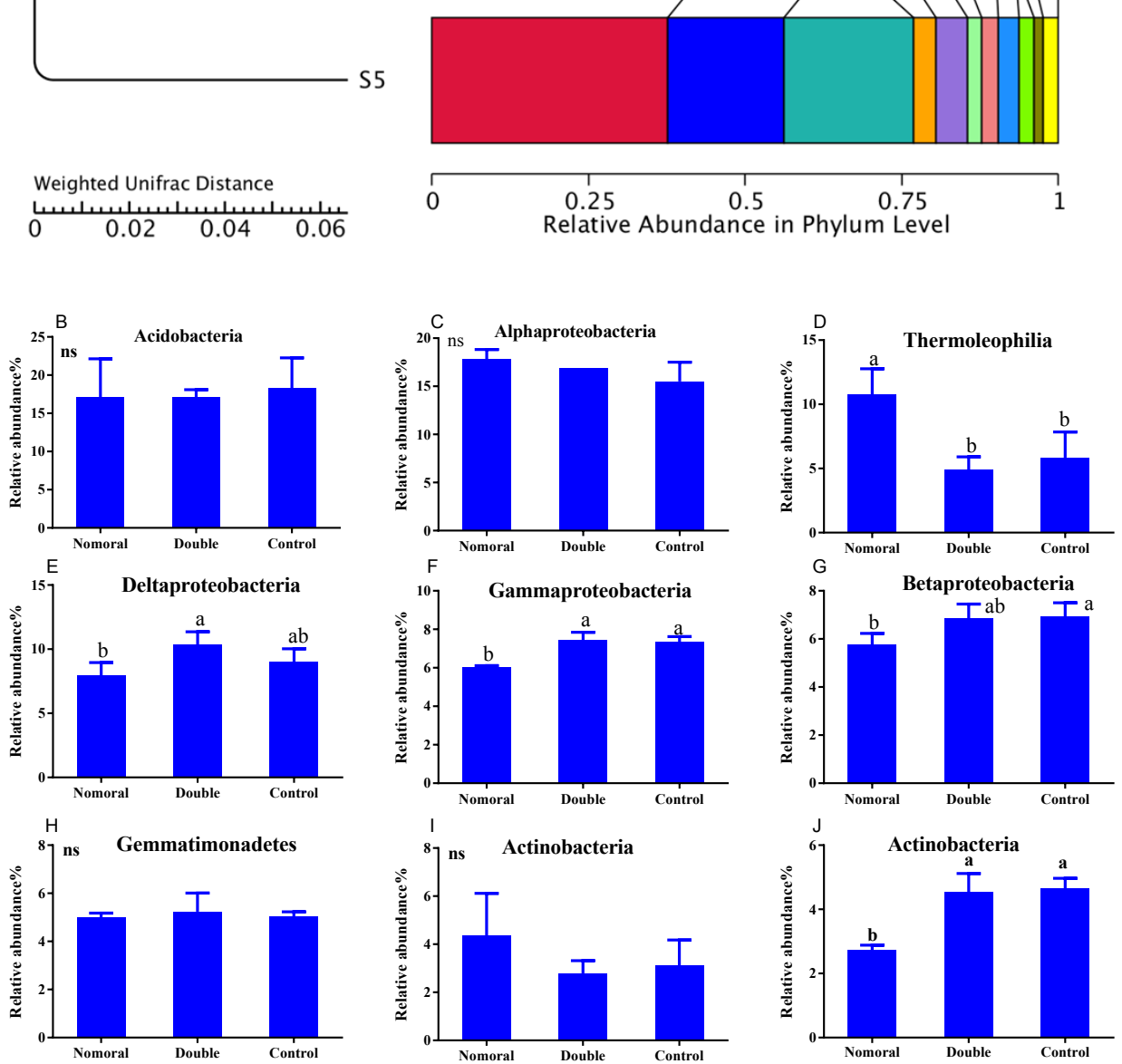

438

Fig .3 Soil bacterial communities under different litter quantities at the phylum level (A) and

litter quantity treatments $(\mathrm{P}<0.05)$; ns indicates that there is no significant difference. All data are expressed as means \pm SD. S0, control; S5, normal treatment; S10 double treatment. 

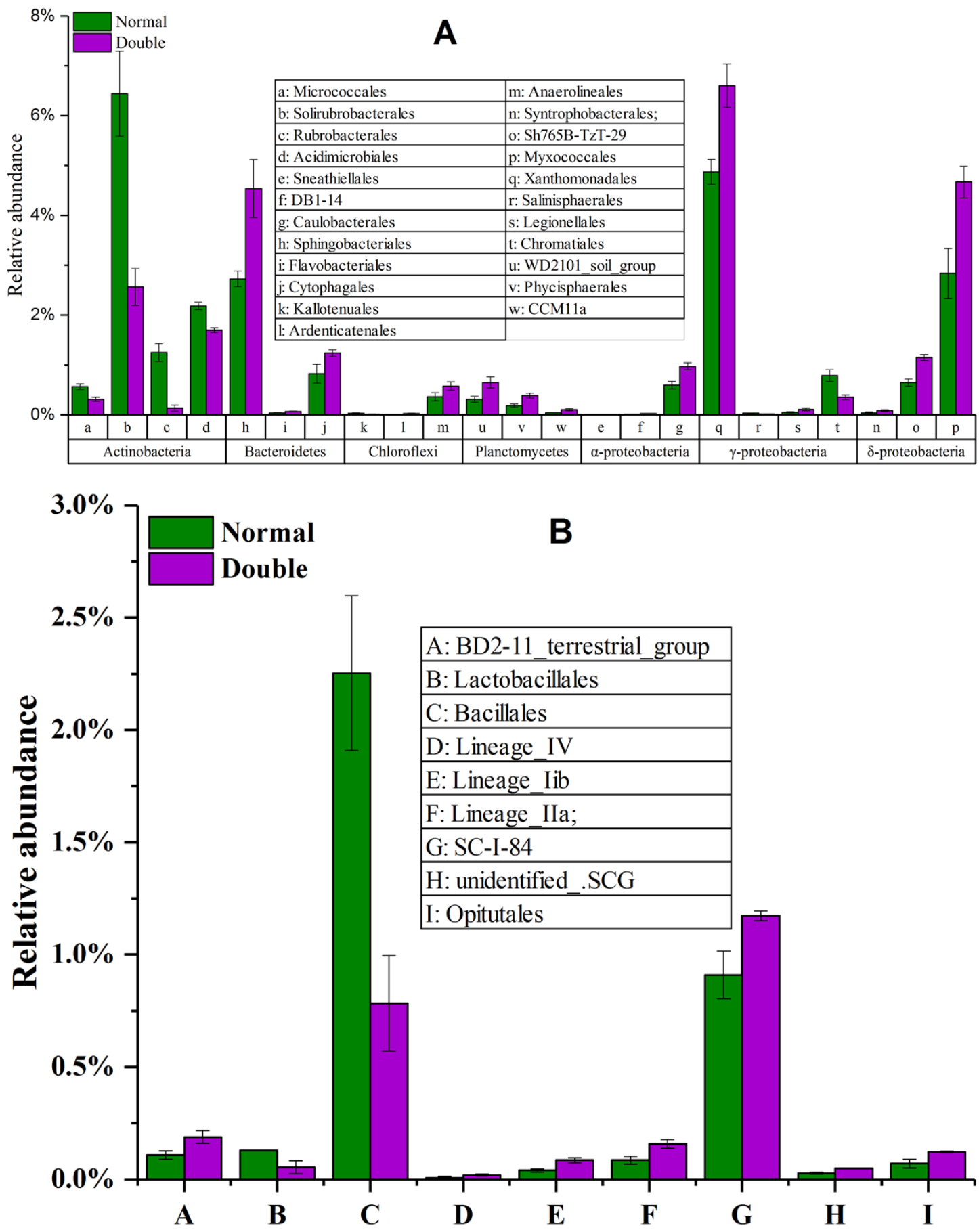

Fig. 4 The significantly different taxa between the normal treatment and the double treatment as determined by a T-test. The taxa shown in the figure were significant at the 0.05 level. All data 
451

452

453

454

455

456

457

458

459

460

461

462

463

464

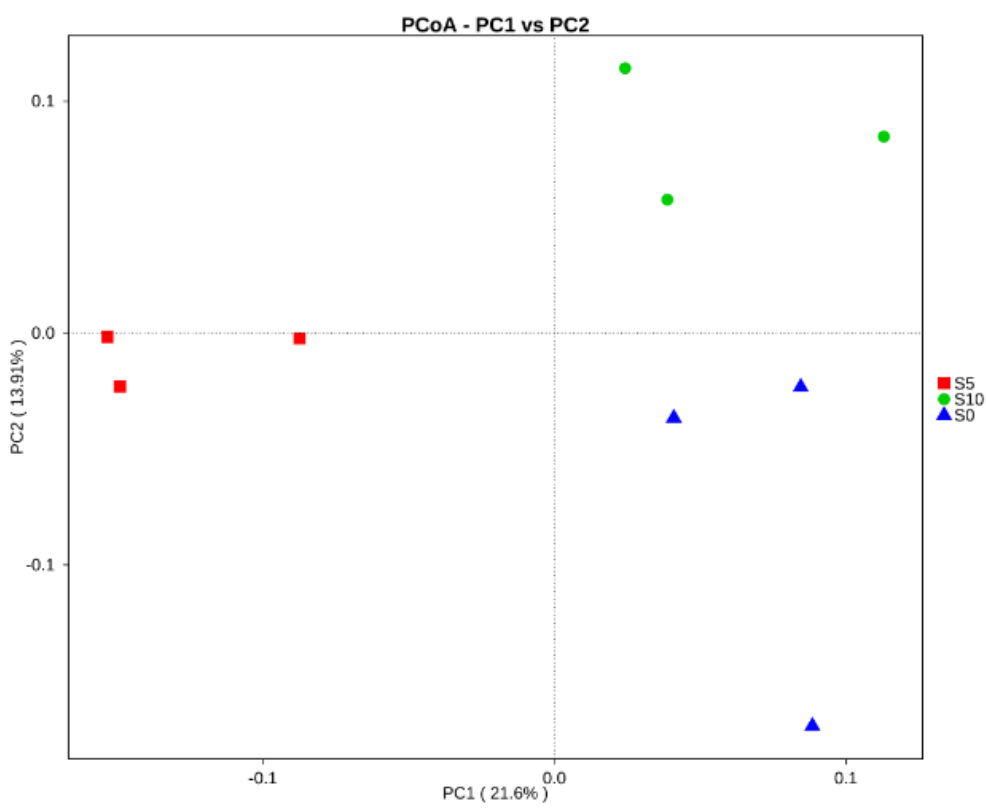

Fig. 5 Principal coordinates analysis (PCoA) of the soil bacterial community composition based on Bray-Curtis distances. S0, control; S5, normal treatment; S10 double treatment. 
465

466

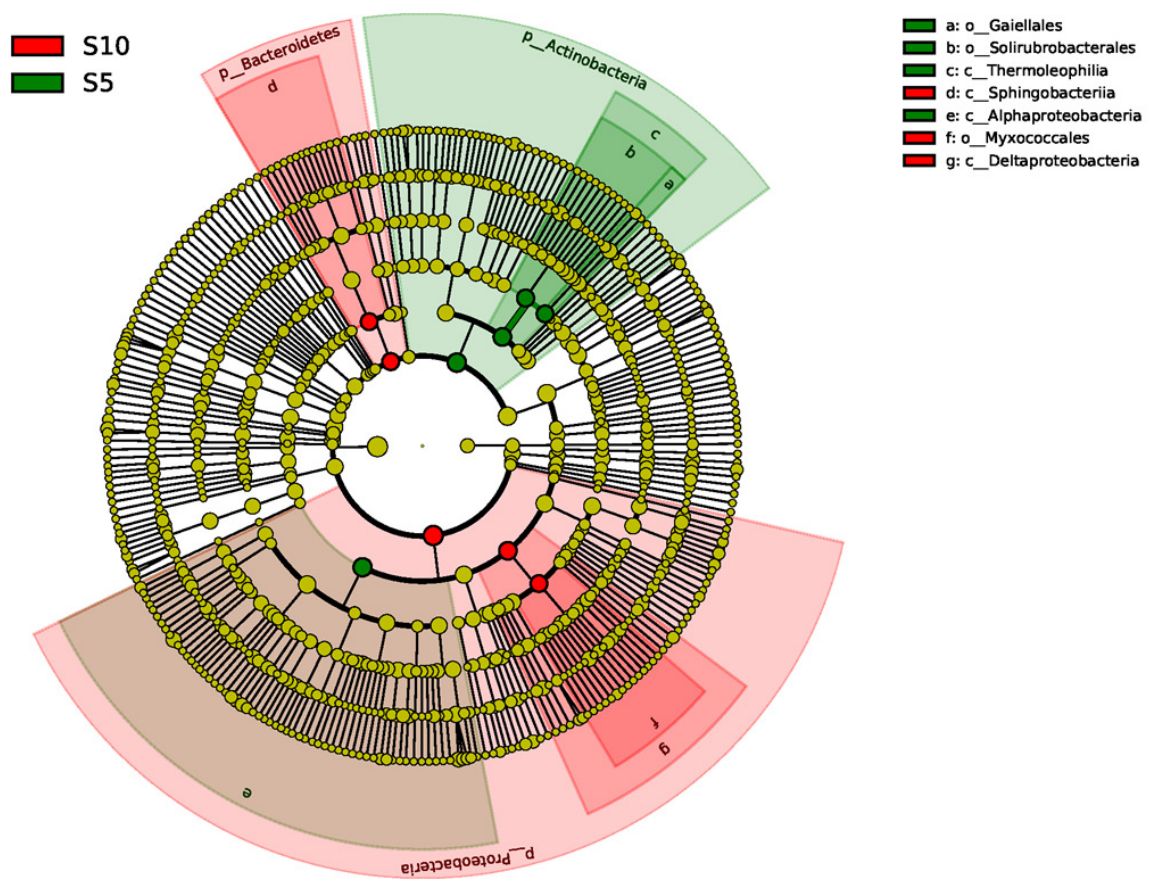

467

468 Fig. 6 A linear discriminant analysis effect size (LEsFe) method identifies the significantly different abundant taxa of bacteria under different litter quantity treatments. Taxa with treatment; S10 double treatment. 
Table 1 Soil bacterial alpha diversity indices under different the litter quantity treatment

\begin{tabular}{ccc}
\hline Treatment & Observed_species & Shannon \\
\hline Normal & $3035 \pm 42$ & $9.57 \pm 0.11$ \\
Double & $2962 \pm 109$ & $9.59 \pm 0.04$ \\
Control & $2932 \pm 62$ & $9.53 \pm 0.10$ \\
\hline
\end{tabular}

481

482

483

484

485

486

487

488

489

490

5

Note: All indices were not significantly different between the different treatments. All data are

expressed as means $\pm \mathrm{SD}$.

Table 2 The Pearson correlations between the soil properties and the soil bacterial community

\begin{tabular}{llllllll}
\hline & $\mathrm{DOC}$ & $\mathrm{DON}$ & $\mathrm{MBC}$ & $\mathrm{MBN}$ & $\mathrm{SM}$ & $\mathrm{NO}_{3}-\mathrm{N}$ & $\mathrm{NH}_{4}-\mathrm{N}$ \\
\hline Proteobacteria & $\mathbf{0 . 7 5 9} *$ & 0.302 & -0.227 & -0.426 & $\mathbf{0 . 6 7 6 *}$ & 0.511 & -0.313 \\
Actinobacteria & -0.648 & $\mathbf{- 0 . 6 8 4} *$ & -0.189 & $\mathbf{0 . 8 1 6 * *}$ & $\mathbf{- 0 . 8 3 9 * *}$ & -0.444 & 0.514 \\
Bacteroidetes & 0.644 & $\mathbf{0 . 8 1 2} *$ & 0.33 & $\mathbf{- 0 . 9 1 5 * *}$ & $\mathbf{0 . 7 4 9 *}$ & 0.26 & -0.306 \\
Verrucomicrobia & 0.114 & $\mathbf{0 . 6 7 9 *}$ & 0.511 & $\mathbf{- 0 . 6 7 4 *}$ & 0.385 & -0.035 & -0.343 \\
Verrucomicrobia & 0.537 & $\mathbf{0 . 6 6 9 *}$ & 0.201 & $\mathbf{- 0 . 7 8 5 *}$ & $\mathbf{0 . 6 7 4} *$ & 0.395 & -0.462 \\
Firmicutes & -0.623 & $\mathbf{- 0 . 8 0 4 * *}$ & -0.262 & $\mathbf{0 . 8 9 7 * *}$ & $\mathbf{- 0 . 8 2 0} * *$ & -0.404 & 0.426 \\
Nitrospirae & 0.563 & $\mathbf{0 . 7 1 5 *}$ & 0.307 & $\mathbf{- 0 . 7 9 7 *}$ & 0.637 & 0.239 & -0.318 \\
\hline
\end{tabular}

Note: DOC: dissolve organic carbon. DON: dissolve organic nitrogen. MBC: microbial biomass

carbon. $\mathrm{MBN}$ : microbial biomass nitrogen. $\mathrm{SM}$ : soil moisture. $\mathrm{NO}_{3}-\mathrm{N}$ : nitrate nitrogen; $\mathrm{NH}_{4}-\mathrm{N}$ :

ammonia nitrogen. * indicate significance at the 0.05 level, ** indicate significant at the 0.007

level (adjusted by Bonferroni correction).

Table 3 ANOSIM and SIMPER analysis between the different litter treatments

\begin{tabular}{ll}
\hline$\square$ SIMPER & ANOSIM
\end{tabular}




\begin{tabular}{llr} 
Group A \& B & Average similarity \% & R value \\
\hline Normal vs Double & 76.28 & 1 \\
Normal vs Control & 76.66 & 0.889 \\
Double vs Control & 81.02 & 0.296 \\
\hline
\end{tabular}

491 